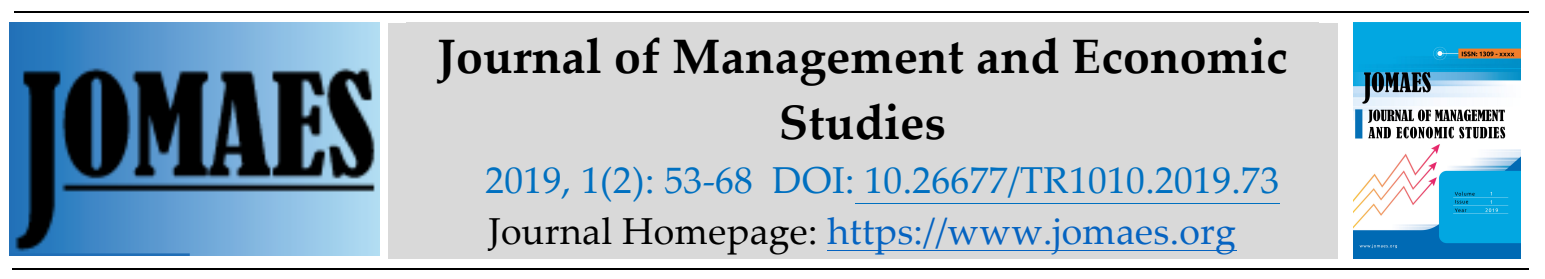

\title{
Risk Attitude, Risk Perception and Risk Management Strategies Adoption in Zimbabwean Small and Medium Enterprises
}

\author{
Ledwin Chimwai \\ Great Zimbabwe University lchimwai@gzu.ac.zw \\ Watson Munyanyi \\ Great Zimbabwe University wmunyanyi@gzu.ac.zw
}

\begin{abstract}
This study seeks to investigate the influence of both perceived risks and risk attitude on the decision by entrepreneurs to adopt risk management strategies.Risk management remains central to the day to day operations of small and medium enterprises, as these constantly need to mitigate risks such as frauds, delinquencies, liquidity and staff turnover. To empirically test a conceptual model of the relationship between the independent variables and the dependent variable, structural equation modelling was employed. A five-point Likert scale questionnaire was used to collect data from 288 small and medium enterprises, while to analyse the data and confirm the existence and strength of conceptualised relationships, a confirmatory factor analysis and a structural equation analysis were conducted. The results of the study provided rather a disparity from the general stereotypical perception about small and medium enterprises, that they largely seek and embrace risk and that they are poorly ranked in terms of risk management adoption. The findings of the study confirm that both perceived risk and risk attitude have a positive and significant relationship to the adoption of risk management strategies by entrepreneurs. In order to enhance adoption of risk management strategies by SMEs, it is important that the perceptions of owners and managers with regard to the probability of occurrence, possibility of impact and severity of impact of a risk event, must be altered.
\end{abstract}

Keywords: Perceived risk, risk attitude, risk management

\section{INTRODUCTION}

Firms today operate in a turbulent business environment and are forced to deal a number of uncontrollable risks emanating from fast technological progresses, unstable customer behaviour, changing business models and intensified regulatory pressure (Slagmulder \& Devoldere, 2018). This dynamism is often characterised by high rapidity, complication, uncertainty, and volatility (Davis, Eisenhardt, \& Bingham, 2009). Given the dynamism in the business environment, risk management remains central to the day to day operations of firms, including small and medium enterprises (SMEs). Regardless of the environment, most 
entrepreneurial activities now require that the entrepreneur pays attention to uncertainty and changes in the environment in order to make sound decisions (McMullen \& Shepherd, 2006). Sound decision-making under risk and uncertainty is a critical element in promoting investment, production, marketing and ultimately a competitive edge (Choudhury \& Goswami, 2014). Firms constantly need to mitigate risks like fraud, delinquencies andemployee turnover. When firmsproperly identify and mitigate the several risks that arise from their operations they enhance their safety and operational competitiveness (Sodhi, Son \& Tang, 2012; Marucheck, Greis, Mena, \& Cai, 2011). From an economics viewpoint, the entrepreneurial decision-making process is regarded as a utility maximization process that largely depends on the expected benefit, while taking into consideration risk and uncertainty (Goswami, Hazarika \& Handique, 2017).Risk management has remained central to entrepreneurship research, largely because entrepreneurs continually face uncertainty and demanding situations in their operations (Wennberg, Delmar \&McKelvie, 2016).The entrepreneur's perception and attitude toward risk is central to the "economic personality" of the entrepreneurial venture, and this makes risk a significant predictor of the performance outcomes of a firm (Gerhardt, SchildbergHörisch \& Willrodt, 2017). Additionally, the manner in which one perceives risk will affect the way they respond to risk, with some endeavouring to reduce the risk at all times while others generally tending to ignore risk and its consequences and increasing it (Le \&Arcodia, 2018).

While a number of scholars previously argued that the prevalence of SMEs and the accompanying widespread informality have led to reduced productivity, lack of innovation capabilities and non-growth orientation (Bauwens \& Lemaitre, 2014), SMEs have continued to play a significant role in economic growth and subsistence of households (Berner, Gomez, \&Knorringa, 2012). In Zimbabwe, the larger share of commercial activities is concentrated in the small and medium enterprises (SMEs) sector and these have both a statutory and obligatory burden to implement risk management mechanisms. The economic crisis that has besieged the country over the past two decades led to some widespread closures of large firms and extensive restructuring and downsizing of SMEs. As is the case with many developing countries, SMEs in Zimbabwe now represent the most genuine employment prospect for most people, especially in the rural areas (Dougherty-Choux, Terpstra, Kammila \& Kurukulasuriya, 2015). After the economic meltdown of 2008, these SMEs were left vulnerable not only financially but also from skills shortage, technology obsolescence, severe legislative requirement and ever-changing customer needs. Empirical evidence on risk management mechanisms in SMEs remains largely scanty and inconclusive than in large firms (Cañamares, Escribano, García, Barriuso \& Sáiz, 2017).

The challenges facing small and medium enterprises (SMEs) in Africa's business environment are well documented and include poor infrastructure services and limited access to financing (Page \&Söderbom, 2015; Crick, Eskander, Fankhauser \& Diop, 2018). However, there is still limited empirical literature on risk management in the SMEs context. This is despite the fact that understanding how to handle risk through proper risk management practices is critical for SMEs if they are to survive, compete and satisfy their customers (ArevaloChavez \&Seow, 2012). This study explores the constructs that potentially explain risk management mechanisms adoption by SMEs in Zimbabwe. It highlights two organization-level factors, namely risk attitude and risk perception, which SME managers and owners as organisational gatekeepers should comprehend heuristically. By exploring the factors influencing risk management strategies adoption, this study representsa critical step toward empowering SMEs and public policy authorities to encourage targeted risk management activities and engagements. Given the fundamental role that risk attitude plays in economic theory and its behaviour predictive capacity, understanding the factors that potentially influence risk attitude is of great importance 
to SMEs and existing literature (Gerhardt, Schildberg-Hörisch \& Willrodt, 2017). Empirical studies have shown that in developing countries ignorance of the risk management processes and general lack of adequate information are the major challenges affecting firms (Kikwasi, 2011; Chileshe \& Kikwasi, 2013; Hwang, Zhao \&Toh, 2014). Besides empirically testing a proposed risk management practices model, this study provides a basis for managerial recommendations to SMEs on risk management. The study also expands the stream of empirical research in risk management which has largely been conducted with large firms in mind or with the quantification and measurement bias.

\section{LITERATURE REVIEW}

In both social and business interactions parties always endeavour to learn the other party's characteristics in order to create their own expectations regarding their behaviour (Büyükboyac1, 2014). As a result, over the decades, scholars have developed interest in how situational variances and individual characteristics affect how entrepreneurs assess risk issues (McCarthy, Puffer \&Lamin, 2018; Mohseni, Jayashree, Rezaei, Kasim \& Okumus, 2018; Lude \& Prügl, 2019). Particularly, risk requires an improved understanding of how firms can better manage risk and effectively develop resilience (VanDerVegt, Essens, Wahlström, \& George, 2015). Because individuals' risk profiling affects the decision-making process, any methodical changes in their inclination towards risk would result in wide-ranging economic and sociopolitical consequences and outcomes (Bonsang \& Dohmen, 2015; Kesavayuth, Ko \& Zikos, 2017). This interest is motivated by the desire to accurately forecast entrepreneurial conduct, and of particular interest is risk attitude and risk perception.

\subsection{Risk Attitude}

People differ in terms of the manner in which they make decisions involving risk and uncertainty and as such these differences are often explained by varying risk attitudes (Jonsson, Söderberg \& Wilhelmsson, 2017). Risk attitude which is a sort of psychological status has been subjected to empirical research in terms of its influence on a number of human and organisational behaviours (Dohmen, Falk, Huffman, Sunde, Schupp\& Wagner, 2011; Hardeweg, Menkhoff \& Waibel, 2013).The notion that individuals are different in terms of their risk tolerance is at the core of the theory of choice (Pratt, 1964). The underlying notion of the theory of choice is that the attitude of an individual towards risk will determine the pertinent outcomes in different contexts like in career choice or portfolio investment (Akgüç, Liu, Tani\& Zimmermann, 2016). Risk attitude relate to the person's intentions to assess a risk situation in a positive or adverse manner and to act accordingly, and the fundamental traits in this are risk propensity and risk aversion (Guan \& Tang, 2018). Zawojska, Bartczak \& Czajkowski, 2019; Abdel-Basset, Gunasekaran, Mohamed \& Chilamkurti, 2019).The risk attitude of an individual represents his specific needs and ranges between risk-propensity and risk-aversion (Rockafellar \& Royset, 2015).It is a significant behavioural characteristic that influences a person's assessment of information and its reliability (Wijayaratna\& Dixit, 2016). For instance, a higher degree of risk aversion may lead to an economic behaviour that generates relatively low income, thus increasing the possibility of poverty (Gloede, Menkhoff \& Waibel, 2015). In the SMEs context, risk attitude plays a pivotal role given the heterogeneity in the performance of SMEs in terms of investment, production and marketing (Goswami, Hazarika \& Handique, 2017). Therefore, the integration of the entrepreneur's risk attitude into the risk management strategies adoption process of SMEs is vital to ensure long lasting solutions. This study considers that and attempts to model a risk management strategies adoption framework which presents the determinants of attitude in SMEs. 


\subsection{Risk Perception}

Risk perception is the subjective, quantifiable and predictive judgment and evaluation of the characteristics and severity of a potential risk (Xu, Feng, Li, Chen \&Jia, 2017). It is the decisionmaker's evaluation of the risk inherent in a situation that is influenced by both probability and magnitude of potential gain or loss. In economic theory the general assumption is that risk perceptions are stable personal characteristics and can be observed over a considerable period of time (Tausch \& Zumbuehl, 2018). It is generally defined as a two-dimensional construct, in terms of the probability and significance of loss (Bauer, 1960; Harbeck, Glendon\& Hine, 2018) and multi-faceted construct, in terms of social, physical, financial, psychological and time loss (Le \&Arcodia, 2018). Risk perception has been measured in terms of the dread and uncontrollable risks, unknown and unobservable risks and extent of the risk exposure (Song, McComas\& Schuler, 2019). These perceptions are largely influenced by both psychological and social factors andare socially constructed based on the subjective views of society (van der Linden, 2015). Risk perceptions in business decision-making are primarily influenced by the relative level of commitment, variability in expected outcomes and any potential losses that may result from the commitment (Forlani\& Mullins 2000; Bishu, Reilly, Lahiff, \& Steiner, 2018). In this study, the general proposition is that risk perceptions of entrepreneurs have a considerable impact on their risk attitude which in turn affects the adoption of risk management strategies. How owners and managers of SMEs respond to the changes in the environment is largely dependent on how they interpret indicators from the business situation (Stroea, Parida \& Wincent, 2018). In addition, it is largely accepted that the way an individual perceives a risky situation influences ability to control the behavioural outcomes which in turn affects the ability to achieve goals and plans (Giordano Martínez, Herrero, Crespo \& Fernández-Laviada, 2017). What is of interest in this study is how risk perceptions will impact on the way SMEs owners and managers evaluate risk.

\subsection{Risk and Risk Management}

In today's business environment, individuals and businesses are faced with increased risk than they were facing in the past, owing to rapid changes, industrialisation and urbanisation. Risk is a function of probable occurrence of a hazard and its possible impacts on a firm hence the need to identify and define potential risks on firm processes or projects (Sepczuk \& Kotulski, 2018). It is evident that risks exist in virtually all business settings and as much as firms may actively manage risk, it will still be apparent (Ho, Zheng, Yildiz \& Talluri, 2015). It however remains imperative that firms take cognisance of both internal and external risks characteristic in their businesses so as to enhance competitiveness and business resilience (Bharwani\& Mathews, 2012). Over the past decades, the risk management notion has become progressively significant in the management of firms thereby influencing business operations and routines (Hayne \& Free, 2014; Power, 2016). Risk management is a continuous process and the decisions that are made in uncertain circumstances are based on the perception that the party has about the environment, their attitudes, and their risk preferences (Saqib, Ahmad, Panezai \& Rana, 2016). In the face of increased attention on risk management, existing literature has focused on the various risk management frameworks, the technologies that promote risk management and the pertinent risk work practices (Themsen \& Skærbæk, 2018). When a risk is properly managed, chances are that there would be a significant reduction on the negative effects of a risky event on the firm. There is consensus among Gaganis, Hasan, Papadimitri and Tasiou (2019) and ShadLai, Fatt, Klemeš and Bokhari (2019) that developing proper risk management strategies that support the crucial pillars of the firms is effective in terms of alleviating the negative effects of a risky event. Therefore, the implementation of risk management activities improves organisational and in turn assist in the attainment of organisational goals and objectives 
efficiently and competently (Wijeratne, Perera\& De Silva, 2014). The dynamism in the business world makes it difficult to foresee future circumstances making it difficult to address risk and opportunity. Because of these shifts in the environment and the resultant new reality, the traditional risk management practices have become outdated and cannot assist a firm address risk and uncertainty (Slagmulder \& Devoldere, 2018). Firms have gradually been forced to move away from traditional risk management approaches which consider a single aspect of risk, to adopt approaches that focus on a number of risk aspects and the firm's overall performance (Wang, Lin, Werner \& Chang, 2018).

\section{CONCEPTUAL FRAMEWORK AND HYPOTHESIS DEVELOPMENT}

The conceptual model used in this study was developed through extensive search of existing literature, primarily the work of Ullah, Jourdain, Shivakoti and Dhakal (2015) who studied the management of catastrophic risks in agriculture in the Khyber Pakhtunkhwa Province of Pakistan. The model was authenticated by existing literature conducted in the process of developing the hypothesis pertinent to this study. The following figure illustrated the conceptual model used in this study.

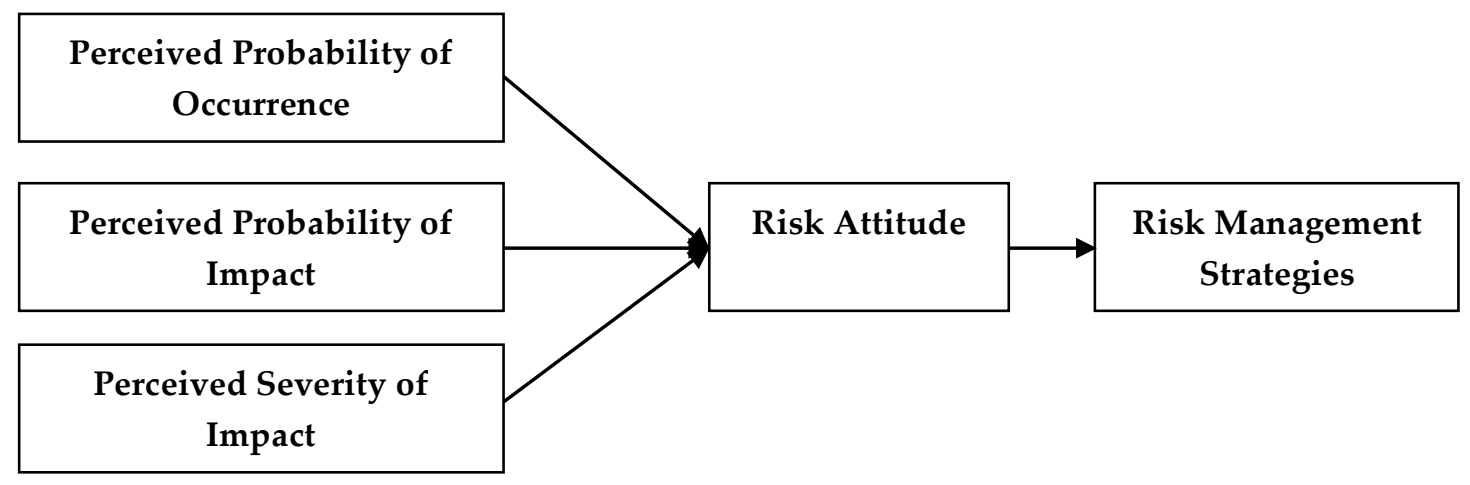

Figure 1. Conceptual Model

\subsection{Perceived Risk and Risk Attitude}

Risk has been theorised as a function of the probability and magnitude of loss associated with events (Tsai, 2018; Moganedi \& Stacey, 2019). This implies that both probability and magnitude are important factors in the build-up of an individual's overall perceptions of risk. It has been empirically proven that risk perceptions influence people's behaviour while increasing the inclination towards taking steps to address the problems at hand (van Schaik, Jansen, Onibokun, Camp \&Kusev, 2018;Martins, Costa, Oliveira, Gonçalves \& Branco, 2019). Understanding better the manner in which individuals comprehend risks is important in order to predict the way they respond to risks, for instance floods and other natural hazards (Wisner \& Caressi-Lopez, 2012). The differences in the exhibited risk perception may lead certain individuals into choosing even riskier paths because they are convinced they can deal with the risks. According to Zhu, Yai, Ma \& Wang (2018) the perceptions that an individual hold about risk stimulate the need for information search, eventually influencing the individual's attitude and in customers, the intention to purchase. Given the arguments presented above, it is appropriate to make the following propositions relating to the relationship between risk perception and risk attitude. 
$H_{1} \quad$ There is a positive and significant relationship between perceived probability of occurrence and risk attitude

$\mathrm{H}_{2} \quad$ There is a positive and significant relationship between perceived probability of impact and risk attitude.

$H_{3} \quad$ There is a positive and significant relationship between perceived severity of consequences and risk attitude.

\subsection{Risk attitude and Risk Management strategies Adoption}

The need for constant transformation in business operations cannot be overemphasised give the deep uncertainty that companies face today. Organisations need to constantly build and deploy their capabilities in order to adapt and reinvent themselves, and this rate of adaptation and prediction of the future must me be adequate enough to address risks and opportunities (Slagmulder \& Devoldere, 2018). Risk management have proved to be relevant to a number of areas including finance, insurance, occupational safety and public health, and the choice of a risk management strategy is a complex, multidimensional decision-making process, difficult to quantify (Tudor, Spaulding, Roy \& Winter, 2014;Alikhani, Torabi\& Altay, 2019). The attitude of an individual towards risk has been described as central to the decision-making process and the modeling of a risk management strategy. A risk-averse person is most likely to opt for a less rewarding avenue over an avenue that is more rewarding but with increased risk. On the contrary, a risk loving person is highly likely to opt for a higher risk alternative in anticipation of a better result (Warshawsky-Livne, Novack, Rosen, Downs, Shkolnik-Inbar \& Pliskin, 2014). Based on the arguments and empirical evidence provided above, the following hypothesis is made.

$H_{4} \quad$ There is a positive and significant relationship between risk attitude and risk management strategies adoption.

\section{METHOD}

\subsection{The study area}

This study sought to investigate the relationship between risk perceptions, risk attitude and risk management strategies adoption in small and medium enterprises. It focussed on the SMEs listed in the 2018 database controlled by the Ministry of Small and Medium Enterprises and Cooperative Development. The database has over 10,000 SMEs but for manageability, the study focused on the 2845 SMEs that updated their records this financial year. This is because this group of SMEs was considered manageable and accessible. From the sampling frame of 2845 SMEs, a sample of 600 SMEs was selected using simple random sampling and to ensure randomness, a computer-based lottery system was employed using the Randomizer software. Of the 600 questionnaires distributed, using the drop and pick up technique, 288 questionnaires were returned and deemed useful for data analysis. The questionnaire used in collecting data had a five-point Likert scale with end points of "strongly disagree" and "strongly agree" and this was made to permit confirmatory factor analysis (CFA) of the constructs which were specified in the conceptual model. Table 1 indicates the demographic characteristics of the sample. 
Table 1: Descriptive statistics of the biographical variables $(\mathrm{N}=\mathbf{2 8 8})$

\begin{tabular}{|l|l|l|l|}
\hline & Frequency & $\begin{array}{l}\text { Percent } \\
\%\end{array}$ & $\begin{array}{l}\text { Cumulative } \\
\%\end{array}$ \\
\hline Business Sector & & & \\
\hline Manufacturing & 88 & 30.56 & 30.56 \\
\hline Retail & 123 & 42.71 & 73.27 \\
\hline Mining & 11 & 3.82 & 77.09 \\
\hline Tourism & 55 & 19.10 & 96.19 \\
\hline Agriculture & 9 & 3.12 & 99.31 \\
\hline Other & 2 & 0.69 & 100 \\
\hline No. of Employees in Org. & & & \\
\hline $0-50$ & 56 & 19.44 & 19.44 \\
\hline $51-100$ & 165 & 57.29 & 76.73 \\
\hline $101-150$ & 22 & 7.64 & 84.37 \\
\hline 151 and more & 45 & 15.63 & 100 \\
\hline Business Annual Turnover & & & \\
\hline$\$ 0-\$ 5,000$ & 75 & 26.04 & 26.04 \\
\hline$\$ 5,001-\$ 10,000$ & 45 & 15.63 & 41.67 \\
\hline$\$ 10,000-\$ 15,000$ & 89 & 30.90 & 72.57 \\
\hline$\$ 15,001$ and more & 79 & 27.43 & 100 \\
\hline
\end{tabular}

Of the 288 respondents that provided responses for this study, the majority were from the retail sector (123 participants), which constituted $42.71 \%$ of the sample. This was followed by the manufacturing sector which had a total of 88 respondents $(30.56 \%)$. In terms of size, most of these SMEs are small, employing below 50 employees while in terms of annual turnover the majority are above $\$ 10,000$. The limited number of employees could be explained by the strategic decision to keep operational costs low, amid poor economic performance in the country.

\subsection{Measurements}

The measurement instrument was guided by previously validated instruments on risk and risk management as well as the PEST (Political, Economic, Social and Technological) Framework that has proved very useful in risk management. The research instrument was developed based on our extensive literature review and was designed to collect information on a number of aspects relating to the behaviour of SMEs with respect to current and future business environment variability. The work of Ullah et al. (2015) contributed significantly to the design of the research instrument. The questionnaire contained five sections. Section A was designed for the purpose of collecting socio-demographic data on respondents while Section Bsolicited data on Perceived Probability of Occurrence. Section C contained questions on Perceived Probability of Impact and Section D was on Risk Attitude. The last section of the questionnaire, Section E solicited questions on Risk Management Strategies Adoption. The construct items were presented based on a 5-point Likert scale affixed on both extreme ends by "strongly disagree" and "strongly agree".

To analyse the data and confirm the conceptual model and hypothesis made, Structural Equation Modeling (SEM), one of the widely used multivariable analysis techniques, was used and analysis was conducted in AMOS 25.0. As stated by Anderson and Gerbing (1988), SEM encompasses the measurement model and the structural model based on the hypothesised relationships among the study's variables, portrayedgraphically. Theinitial stage involved the 
evaluation and estimation of the measurement model usingconfirmatory factor analysis (CFA). CFA as also employed to test for reliability andvalidity of the measurement instrument. The second stage involved a structural modelanalysis meantto verify the hypothesised relationships given the assumption of a satisfactory measurement model.

\section{RESULTS}

\subsection{Confirmatory Factor Analysis (CFA)}

CFA is conducted to assess unidimensionality, convergent and discriminant validity, as well as reliability (Awang\& Mohammad, 2015) and it is performed on all latent variables before testing for the direction and strength of the interrelationship in SEM. Unidimensionality relates the acceptability of the construct items in terms of acceptable factor loadings which should be 0.60 and above (Hu \& Bentler, 1999). Unidimensionality must be assessed prior to evaluating convergent and discriminant validity, and reliability. The results presented in Table 2 indicated that all the construct items fared well in terms of unidimensionality because the factor loadings well all above .60. Thereafter, the measurement model was examined in order to sanitise and improve on its goodness of fit.

\subsubsection{Measurement model}

The measurement model must be validated for goodness of fit first before the hypothesised causal relationships among the constructs can be validated. Goodness of fit related to how well the model fits a set of observations and it generally summarises the discrepancy between observed values. To validate the fitness in the structure of the measurement model, the comparative fit index (CFI), the root mean square error of approximation (RMSEA) and the chisquare-degrees of freedom ratio (X2/df) were employed (Steiger, 1990). The results showed as CFI value of .963, a RMSEA of .043 and aX2/df value of 1.814 . and according to the recommendations by Hu \&Bentler (1998) and Segars\& Grover (1998)the measurement model was fit enough to allow for hypothesis testing.

Table 1: Measurement Model Goodness-of-fit Assessment

\begin{tabular}{lcccccccc}
\hline Model & $\mathrm{x} 2$ & $\mathrm{df}$ & $\mathrm{p}$ & $\mathrm{x}^{2} / \mathrm{df}$ & SRMR & $\mathrm{CFI}$ & $\mathrm{TLI}$ & RMSEA \\
\hline Acceptable fit thresholds & & & & $<2$ & $<0.05$ & $\geq .95$ & $\geq .95$ & $<0.08$ \\
Structural Model & 1088.00 & 600 & $* * *$ & 1.814 & 0.0456 & 0.963 & 0.959 & 0.043
\end{tabular}

Notes: $\mathrm{x}^{2}$ - Chi-square; $\mathrm{df}$ - degrees of freedom; $\mathrm{p}$ - probability value; SRMR - standardized root; mean square residual; CFI - comparative fit index; TLI - Tucker Lewis index; RMSEA root; mean square errors of approximation

\subsubsection{Reliability and Validity}

Second, in our CFA measurement model for construct reliability and validity. Reliability of a measuring instrument relates to the fact that an instrument should consistently reflect on the construct or variable it is measuring. In this study, scale reliability was measured in terms of the Cronbach alpha. The Cronbach's alpha statistic measures the degree of internal consistencythat is the extent to which the responses given are consistent across the items within a construct. Generally, values above 0.7 for the alpha are acceptable especially for ability tests, and because the Cronbach alpha ranged between 0.724 and 0.875, internal consistency was achieved. In addition, composite reliability values ranged between 0.801 and 0.855 as shown in Table 2 and the AVEs for all the constructs were greater than 0.50. That standardized factor loading for all variables fell between 0.803 and 0.960indicating convergent validity according to Hair Jr, Black, Babin, Anderson \& Tatham (2010). 
Table 2: Descriptive Statistics, Reliability and Validity Assessment

\begin{tabular}{|c|c|c|c|}
\hline Construct item & Mean & Stddev & $\begin{array}{l}\text { Std } \\
\text { estimate }\end{array}$ \\
\hline \multicolumn{4}{|l|}{ Perceived Probability of Occurrence $(\alpha=0.724, \mathrm{CR}=0.822, \mathrm{AVE}=0.537)$} \\
\hline We expect the economic fundamentals to change in future. & 4.03 & .912 & .797 \\
\hline We admit that the political landscape may change in the future. & 4.21 & .940 & .727 \\
\hline The demands and expectations of customers may change in future. & 4.11 & .943 & .736 \\
\hline Our firm accepts that technologies changes are highly likely in future. & 3.89 & .991 & .672 \\
\hline \multicolumn{4}{|l|}{ Perceived Probability of Impact $(\alpha=0.817, \mathrm{CR}=0.874, \mathrm{AVE}=0.635)$} \\
\hline The changes in the economy will affect our firm operations too. & 3.40 & 1.011 & .880 \\
\hline Our firm is vulnerable to the changes in the political landscape. & 3.99 & 1.048 & .767 \\
\hline If customer preferences change, this will affect our business operations. & 3.81 & 1.046 & .745 \\
\hline Our firm will be affected by technological changes if they occur. & 3.98 & 1.036 & .789 \\
\hline \multicolumn{4}{|l|}{ Perceived Severity of Impact $(\alpha=0.875, \mathrm{CR}=0.835, \mathrm{AVE}=0.559)$} \\
\hline We are likely to experience a fall in our return on earning if the environment changes. & 3.09 & .948 & .798 \\
\hline $\begin{array}{l}\text { Undesirable changes in the business environment will affect our profit margins } \\
\text { severely. }\end{array}$ & 3.11 & .917 & .731 \\
\hline A fall in clientele base is likely to be experienced if the status quo changes negatively. & 3.13 & .861 & .750 \\
\hline High staff turnover is a possibility if the business environment changes negatively. & 3.07 & .903 & .710 \\
\hline \multicolumn{4}{|l|}{ Risk Attitude $(\alpha=0.818, \mathrm{CR}=0.801, \mathrm{AVE}=0.553)$} \\
\hline We avoid decisions which bring forth either severe losses. & 3.53 & 1.018 & 0.750 \\
\hline Our firm is reluctant to adopt innovations, until they see their advantages. & 3.45 & 1.083 & 0.701 \\
\hline We value existing profit more than non-guaranteed profit. & 3.44 & 1.000 & 0.802 \\
\hline Before taking high risk probability decisions, we discuss as a firm. & 3.53 & 1.064 & 0.721 \\
\hline \multicolumn{4}{|l|}{ Risk Management Strategies Adoption $(\alpha=0.851, \mathrm{CR}=0.885, \mathrm{AVE}=0.553)$} \\
\hline We have considerable diversification strategies in place in our firm. & 3.83 & .985 & 0.850 \\
\hline Our business contracts protect ourselves against business related changes. & 3.88 & .942 & 0.751 \\
\hline Our firm spreads sales across traders and manufacturers. & 3.99 & .939 & 0.822 \\
\hline Our pricing mechanism is intended to safeguard the market from competition & 4.03 & .912 & 0.821 \\
\hline
\end{tabular}

Table 3 presents that the square roots of AVEs were greater than the cross-correlations between constructs, indicating the acceptable discriminant validity.

Table 3: Square Root of AVE and Correlations of Constructs

\begin{tabular}{|c|c|c|c|c|c|c|c|c|}
\hline & & CR & AVE & 1 & 2 & 3 & 4 & 5 \\
\hline Perceived Probability o & currence & .822 & .537 & 0.733 & & & & \\
\hline Perceived Probability o & pact & .874 & .635 & 0.645 & 0.797 & & & \\
\hline Perceived Severity of In & & .835 & .559 & 0.626 & 0.666 & 0.748 & & \\
\hline Risk Attitude & & .801 & .553 & 0.625 & 0.640 & 0.692 & 0.744 & \\
\hline $\begin{array}{l}\text { Risk Management } \\
\text { Adoption }\end{array}$ & Strategies & .885 & .553 & 0.600 & 0.650 & 0.696 & 0.739 & 0.744 \\
\hline
\end{tabular}

Bold are the square roots of AVE on the diagonal.

The square root of each of the AVEs was larger than the related inter-construct correlations, thereby creating reasonable grounds for the conclusion that discriminant validity is achieved in line with the recommendations of Fornell \& Larcker (1981). In the final analysis, there is evidence that the measurement model exhibited acceptable validity and reliability and that structural analysis and hypothesis testing can be conducted.

\subsubsection{Structural Model Analysis}

In path analysis both endogenous and exogenous variables are involved, and the endogenous variable can either be outcome variables and/or predictors while exogenous variables are solely 
predictors. Unlike regression analysis, path analysis permits the estimation of all the model parameters at the same time, which brings about efficiency and reliability in estimation.

Table 4: Hypothesized relationships among variables

\begin{tabular}{|l|l|l|l|l|l|}
\hline & Hypotheses & $\begin{array}{l}\mathrm{t}- \\
\text { statistic }\end{array}$ & $\begin{array}{l}\text { Path } \\
\text { Coefficient }\end{array}$ & $\begin{array}{l}\mathrm{p}- \\
\text { value }\end{array}$ & Decision \\
\hline$H_{1}$ & $\begin{array}{l}\text { Perceived Probability of Occurrence } \rightarrow \text { Risk } \\
\text { Attitude }\end{array}$ & 11.255 & .786 & $* * *$ & Supported \\
\hline$H_{2}$ & $\begin{array}{l}\text { Perceived Probability of Impact } \rightarrow \text { Risk } \\
\text { Attitude }\end{array}$ & 4.813 & .354 & $* * *$ & Supported \\
\hline$H_{3}$ & $\begin{array}{l}\text { Perceived Severity of Impact } \rightarrow \text { Risk } \\
\text { Attitude }\end{array}$ & 3.095 & .102 & $* * *$ & Supported \\
\hline$H_{4}$ & $\begin{array}{l}\text { Risk Attitude } \rightarrow \text { Risk Management } \\
\text { Strategies Adoption }\end{array}$ & 10.231 & .546 & $* * *$ & Supported \\
\hline
\end{tabular}

The results presented in Table 4 indicate that all the four proposed hypotheses, $\mathrm{H} 1-\mathrm{H} 4$ are fully supported at $\mathrm{p}<0.001$ level of significance. As presented in the results, Perceived Probability of Occurrence of a risk event has a positive and significant influence on the Risk Attitude of a firm $(\beta=0.786, t=11.255, p<0.001)$, as proposed in Hypothesis 1 . The second hypothesis of this study was that there is a significant and positive relationship between Perceived Probability of Impact and Risk Attitude in SMEs. The results on Hypothesis (H2) indicate that, also the hypothesis is supported at 0.001 level of significance $(\beta=0.354 \mathrm{t}=4.813)$. Another relationship that the study sought to verify is the relationship between Perceived Severity of Impact and Risk Attitude. This relationship was proposed in $\mathrm{H} 3$ and the results from the study indicated the there is a positive and significant relationship between these two variables $(\beta=0.102 t=3.095)$, although the relationship was less significant compared to $\mathrm{H} 1$ and $\mathrm{H} 2$. As expected research finding showed that there is a significant and positive relationship between risk attitude and risk management strategies adoption. The path coefficient for the relationship was .546 with at tstatistic of 10.231 at less than 0.001 level of significance. In a nutshell, all the four hypotheses were empirically and significantly supported.

\section{DISCUSSIONS AND CONCLUSIONS}

The results of the study provided rather a disparity from the general stereotypical perception about small and medium enterprises, that they largely seek and embrace risk and that they are poorly ranked in terms of risk management adoption. This study highlights that owners and managers of SMEs do consider certain circumstances as risky and do adopt strategies to evade that risk. This study also sought the level of risk perception of small business owners and the results indicate that the risk perception of entrepreneurs do have a positive influence on the risk attitude, in this case risk aversion. However, it can be noted that their perceived severity of impact has the least effect on risk attitude. It is important therefore that managers and owners of SMEs steer up and refine their risk measurement capabilities in order to be able to evaluate more the financial and operational impact of a risk. Considering the findings of this study, it is appropriate to suggest that it will be inappropriate to generalise the notion that SMEs have high risk propensities and that their risk management abilities are poor. This study shows that such entrepreneurial decision differ within this context.The study presents a plethora of valuabletheoretical implications. It provides empirical support for the proposed conceptual model proposed in the study and since the model can be empirical confirmed it can be used in future risk management researches in the SMEs context. In order to enhance adoption of risk 
management strategies by SMEs, it is important that the perceptions of owners and managers with regard to the probability of occurrence, possibility of impact and severity of impact of a risk event, must be altered. SME education on policy changes, policy implications will enable then to have the right perception and correct their risk attitude and risk adoption. This is key in sustainable growth of the SME sector so that they do not remain risk averse but take risks to earn better returns. If incorporated into policy and practical tools, risk management base policies will assist in making it clearer for SMEs to understand the level of their exposure torisks enabling them to alter their risk attitude and hence adopt the relevant risk management strategies. There are a number of managerial implications for managers that emerge from this study. The conceptual model provided in this study offer supplemental and handy insights into risk and small business management, specifically regarding the development of risk perceptions and attitudes that bring long-term business success. Notably, top management in SMEs should embrace strategies that concietise employees on perceived probability of occurrence and impact from a risk event as well as the perceived severity of the impact. This will develop the right attitude among employees and help them in planning and managing the risk inherent in their work stations in a way that brings effectiveness and sustainability. Risk assessment and knowledge sharing initiatives must be encouraged as SMEs will largely derive benefits from improved risk management strategies adoption. Furthermore, through sharing means such as workshops and seminars employees are encouraged to share risk related best practices. Fundamentally, significance should be placed to the identification and understanding of the firm's sources and types of risk as a way of ensuring that there is a general reduction and improved mitigation of these risk and this would impact on the firm's overall performance.

\section{REFERENCES}

Abdel-Basset, M., Gunasekaran, M., Mohamed, M., \& Chilamkurti, N. (2019). “A framework for risk assessment, management and evaluation: Economic tool for quantifying risks in supply chain". Future Generation Computer Systems, 90, 489-502.

Akgüç, M., Liu, X., Tani, M., \& Zimmermann, K. F. (2016). “Risk attitudes and migration”. China Economic Review, 37, 166-176.

Alikhani, R., Torabi, S. A., \& Altay, N. (2019). "Strategic supplier selection under sustainability and risk criteria". International Journal of Production Economics, 208, 69-82.

Anderson, J., \&Gerbing, D. (1988). Structural modelling in practice: a review and recommended two-step approach. Psychological Bulletin, 103(3), 411-423.

Arevalo Chavez, P. J., \& Seow, C. (2012). “Managing food quality risk in global supply chain: a risk management framework". International Journal of Engineering Business Management, 4(Godište 2012), 1-8.

Awang, M., \& Mohammad, A. H. (2015). "Reliability and Validity of Facilities Management Competencies Instrument Using Partial Least Squares". International Journal of Social Science and Humanity, 5(1), 95.

Bauer, R. A. (1960). "Consumer behavior as risk taking". In R. S. Hancock (Ed.), "Dynamic marketing for a changing world". Chicago: American Marketing Association, 389-398.

Bauwens, T., \&Lemaître, A. (2014). "Popular economy in Santiago de Chile: State of affairs and challenges". World Development, 64, 65-78. 
Berner, E., Gomez, G., \& Knorringa, P. (2012). “'Helping a large number of people become a little less poor': The logic of survival entrepreneurs". The European Journal of Development Research, 24(3), 382-396.

Bharwani, S., \& Mathews, D. (2012). “Risk identification and analysis in the hospitality industry: Practitioners' perspectives from India". Worldwide Hospitality and Tourism Themes, 4(5), 410-427.

Bishu, K. G., O’Reilly, S., Lahiff, E., \& Steiner, B. (2018). “Cattle farmers' perceptions of risk and risk management strategies: evidence from Northern Ethiopia". Journal of Risk Research, 21(5), 579-598.

Bonsang, E., \&Dohmen, T. (2015). "Risk attitude and cognitive aging". Journal of Economic BehaviorE Organization, 112, 112-126.

Büyükboyac1, M. (2014). “Risk attitudes and the stag-hunt game”. Economics Letters, 124(3), 323325.

Cañamares, M. S., Escribano, B. V., García, M. G., Barriuso, A. R., \&Sáiz, A. R. (2017). "Occupational risk-prevention diagnosis: A study of construction SMEs in Spain". Safety science, 92, 104-115.

Chileshe, N., \& Kikwasi, G. J. (2013). "Perception of barriers to implementing risk assessment and management practices by construction professionals in Tanzania". Management, 11371146.

Choudhury, H. K., \& Goswami, K. (2014). "Do different approaches to measurement of risk behaviour yield different results?". Agricultural Economics Research Review, 27(1).

Crick, F., Eskander, S. M., Fankhauser, S., \& Diop, M. (2018). “How do African SMEs respond to climate risks? Evidence from Kenya and Senegal". World Development, 108, 157-168.

Davis, J. P., Eisenhardt, K. M., \& Bingham, C. B. (2009). “Optimal structure, market dynamism, and the strategy of simple rules". Administrative Science Quarterly, 54(3), 413-452.

Dohmen, T., Falk, A., Huffman, D., Sunde, U., Schupp, J., \& Wagner, G. G. (2011). “Individual risk attitudes: Measurement, determinants, and behavioral consequences". Journal of the European Economic Association, 9(3), 522-550.

Dougherty-Choux, L., Terpstra, P., Kammila, S., \& Kurukulasuriya, P. (2015). “Adapting from the ground up. Enabling small businesses in developing countries to adapt to climate change". World Resources Institute and United Nations Development Programme. Washington DC.

Forlani, D., \& Mullins, J. W. (2000). "Perceived risks and choices in entrepreneurs' new venture decisions". Journal of Business Venturing, 15(4), 305-322.

Fornell, C., \& Larcker, D. F. (1981). "Structural equation models with unobservable variables and measurement error: Algebra and statistics". Journal of marketing research, 382-388.

Fung, T. K., Griffin, R. J., \& Dunwoody, S. (2018). Testing Links Among Uncertainty, Affect, and Attitude Toward a Health Behavior. Science Communication, 40(1), 33-62.

Gaganis, C., Hasan, I., Papadimitri, P., \& Tasiou, M. (2019). “National culture and risk-taking: Evidence from the insurance industry". Journal of Business Research, 97, 104-116.

Gerhardt, H., Schildberg-Hörisch, H., \& Willrodt, J. (2017). “Does self-control depletion affect risk attitudes?". European Economic Review, 100, 463-487. 
Giordano Martínez, K. R., HerreroCrespo, Á., \& Fernández-Laviada, A. (2017). “Influence of perceived risk on entrepreneurial desirability and feasibility: multidimensional approach for nascent entrepreneurs". Journal of Risk Research, 20(2), 218-236.

Gloede, O., Menkhoff, L., \& Waibel, H. (2015). "Shocks, individual risk attitude, and vulnerability to poverty among rural households in Thailand and Vietnam". World Development, 71, 54-78.

Goswami, K., Hazarika, B., \& Handique, K. (2017). "Determinants of financial risk attitude among the handloom micro-entrepreneurs in North East India". Asia Pacific Management Review, 22(4), 168-175.

Guan, Y., \& Tang, D. Y. (2018). “Employees' risk attitude and corporate risk taking: Evidence from pension asset allocations". Journal of Corporate Finance, 48, 261-274.

Hair Jr, J. F., Black, W. C., Babin, B. J., Anderson, R. E., \& Tatham, R. L. (2010). “SEM: An introduction". Multivariate Data Analysis: A Global Perspective, 629-686.

Harbeck, E. L., Glendon, A. I., \& Hine, T. J. (2018). "Young driver perceived risk and risky driving: A theoretical approach to the "fatal five"". Transportation research part F: traffic psychology and behaviour, 58, 392-404.

Hardeweg, B., Menkhoff, L., \& Waibel, H. (2013). “Experimentally validated survey evidence on individual risk attitudes in rural Thailand". Economic Development and Cultural Change, 61(4), 859-888.

Hayne, C., \& Free, C. (2014). "Hybridized professional groups and institutional work: COSO and the rise of enterprise risk management". Accounting, Organizations and Society, 39(5), 309-330.

Ho, W., Zheng, T., Yildiz, H., \& Talluri, S. (2015). Supply chain risk management: a literature review. International Journal of Production Research, 53(16), 5031-5069.

Hu, L. T., \& Bentler, P. M. (1999). “Cutoff criteria for fit indexes in covariance structure analysis: Conventional criteria versus new alternatives". Structural equation modeling: a multidisciplinary journal, 6(1), 1-55.

Hwang, B. G., Zhao, X., \&Toh, L. P. (2014). Risk management in small construction projects in Singapore: Status, barriers and impact. International Journal of Project Management, 32(1), 116-124.

Jonsson, S., Söderberg, I. L., \& Wilhelmsson, M. (2017). "An investigation of the impact of financial literacy, risk attitude, and saving motives on the attenuation of mutual fund investors' disposition bias". Managerial Finance, 43(3), 282-298.

Kesavayuth, D., Ko, K. M., \& Zikos, V. (2018). "Locus of control and financial risk attitudes". Economic Modelling, 72, 122-131.

Kikwasi, G. J. (2011). "An assessment of risk management practices by consultants in Tanzania". Proceedings of the 6th Built Environment. Johannesburg, South Africa, 31, 302-314.

Le, T. H., \& Arcodia, C. (2018). "Risk perceptions on cruise ships among young people: Concepts, approaches and directions". International Journal of Hospitality Management, 69, $102-112$.

Le, T. H., \&Arcodia, C. (2018). "Risk perceptions on cruise ships among young people: Concepts, approaches and directions". International Journal of Hospitality Management, 69, $102-112$. 
Lude, M., \& Prügl, R. (2019). "Risky decisions and the family firm bias: An experimental study based on prospect theory". Entrepreneurship Theory and Practice, 1-23.

Martins, J., Costa, C., Oliveira, T., Gonçalves, R., \& Branco, F. (2019). How smartphone advertising influences consumers' purchase intention. Journal of Business Research, 94, 378387.

Marucheck, A., Greis, N., Mena, C., \& Cai, L. (2011). "Product safety and security in the global supply chain: Issues, challenges and research opportunities". Journal of Operations Management, 29(7-8), 707-720.

McCarthy, D. J., Puffer, S. M., \& Lamin, A. (2018). “Entrepreneurial orientation in a hostile and turbulent environment: risk and innovativeness among successful Russian entrepreneurs". European Journal of International Management, 12(1-2), 191-221.

McMullen, J. S., \& Shepherd, D. A. (2006). "Entrepreneurial action and the role of uncertainty in the theory of the entrepreneur". Academy of Management review, 31(1), 132-152.

Moganedi, K. A., \& Stacey, T. R. (2019). "Value creation as an approach to the management and control of rockburst damage in tunnels". Tunnelling and Underground Space Technology, 83, 545-551.

Mohseni, S., Jayashree, S., Rezaei, S., Kasim, A., \& Okumus, F. (2018). "Attracting tourists to travel companies' websites: the structural relationship between website brand, personal value, shopping experience, perceived risk and purchase intention". Current Issues in Tourism, 21(6), 616-645.

Page, J., \& Söderbom, M. (2015). “Is small beautiful? Small enterprise, aid and employment in Africa". African Development Review, 27(S1), 44-55.

Power, M. (Ed.). (2016). Riskwork: Essays on the organizational life of risk management. Oxford University Press.

Pratt, J.W., 1964. "Risk aversion in the small and in the large". Econometrica, 32, 122-136.

Rockafellar, R. T., \& Royset, J. O. (2018). “Superquantile/CVaR risk measures: Second-order theory". Annals of Operations Research, 262(1), 3-28.

Saqib, S. E., Ahmad, M. M., Panezai, S., \& Rana, I. A. (2016). An empirical assessment of farmers' risk attitudes in flood-prone areas of Pakistan. International Journal of Disaster Risk Reduction, 18, 107-114.

Segars, A. H., \& Grover, V. (1998). "Strategic information systems planning success: an investigation of the construct and its measurement". MIS quarterly, 139-163.

Sepczuk, M., \& Kotulski, Z. (2018). "A new risk-based authentication management model oriented on user's experience". Computers \& Security, 73, 17-33.

Shad, M. K., Lai, F. W., Fatt, C. L., Klemeš, J. J., \& Bokhari, A. (2019). “Integrating sustainability reporting into enterprise risk management and its relationship with business performance: A conceptual framework". Journal of Cleaner Production, 208, 415-425.

Slagmulder, R., \& Devoldere, B. (2018). “Transforming under deep uncertainty: A strategic perspective on risk management". Business Horizons, 61(5), 733-743.

Sodhi, M. S., Son, B. G., \& Tang, C. S. (2012). "Researchers' perspectives on supply chain risk management". Production and operations management, 21(1), 1-13. 
Song, H., McComas, K. A., \& Schuler, K. L. (2019). “Hunters' responses to urine-based scent bans tackling chronic wasting disease". The Journal of Wildlife Management.83 (2), 457-466.

Steiger, J. H. (1990). "Structural model evaluation and modification: An interval estimation approach". Multivariate Behavioral Research, 25(2), 173-180.

Stroe, S., Parida, V., \& Wincent, J. (2018). “Effectuation or causation: An fsQCA analysis of entrepreneurial passion, risk perception, and self-efficacy". Journal of Business Research,89, 265-272.

Tausch, F., \& Zumbuehl, M. (2018). Stability of risk attitudes and media coverage of economic news. Journal of Economic BehaviorE Organization, 150, 295-310.

Tsai, C. H. (2018). Seismic risk assessment and design of tourism buildings using probability analysis. International Journal of Emergency Management, 14(1), 90-106.

Tudor, K., Spaulding, A., D. Roy, K., \& Winter, R. (2014). “An analysis of risk management tools utilized by Illinois farmers". Agricultural Finance Review, 74(1), 69-86.

Ullah, R., Jourdain, D., Shivakoti, G. P., \& Dhakal, S. (2015). “Managing catastrophic risks in agriculture: simultaneous adoption of diversification and precautionary savings". International Journal of Disaster Risk Reduction, 12, 268-277.

Van der Linden, S. (2015). "The social-psychological determinants of climate change risk perceptions: Towards a comprehensive model". Journal of Environmental Psychology, 41, 112-124.

Van Der Vegt, G. S., Essens, P., Wahlström, M., \& George, G. (2015). “Managing risk and resilience". Academy of Management Journal, 58(4), 971-980.

van Schaik, P., Jansen, J., Onibokun, J., Camp, J., \& Kusev, P. (2018). Security and privacy in online social networking: Risk perceptions and precautionary behaviour. Computers in Human Behavior, 78, 283-297.

Wang, T. S., Lin, Y. M., Werner, E. M., \& Chang, H. (2018). “The relationship between external financing activities and earnings management: Evidence from enterprise risk management". International Review of Economics \& Finance.58, 312-329.

Warshawsky-Livne, L., Novack, L., Rosen, A. B., Downs, S. M., Shkolnik-Inbar, J., \& Pliskin, J. S. (2014). Gender differences in risk attitudes. In Preference Measurement in Health (pp. 123140). Emerald Group Publishing Limited.

Wennberg, K., Delmar, F., \& McKelvie, A. (2016). “Variable risk preferences in new firm growth and survival". Journal of Business Venturing, 31(4), 408-427.

Wijayaratna, K. P., \& Dixit, V. V. (2016). "Impact of information on risk attitudes: Implications on valuation of reliability and information". Journal of Choice Modelling, 20, 16-34.

Wijeratne, W. M. P. U., Perera, B. A. K. S., \& De Silva, L. (2014). “Identification and assessment risks in maintenance operations". Built Environment Project and Asset Management, 4(4), 384-405.

Wisner, B. \& Caressi-Lopez, A. (2012). Disaster Management: International Lessons in Risk Reduction, Response and Recovery. London: Earthscan.

Xu, G., Feng, X., Li, Y., Chen, X., \& Jia, J. (2017). “Environmental risk perception and its influence on well-being". Chinese Management Studies, 11(1), 35-50. 
Zawojska, E., Bartczak, A., \& Czajkowski, M. (2019). “Disentangling the effects of policy and payment consequentiality and risk attitudes on stated preferences".Journal of Environmental Economics and Management, 93, 63-84.

Zhu, W., Yao, N., Ma, B., \& Wang, F. (2018). “Consumers' risk perception, information seeking, and intention to purchase genetically modified food: An empirical study in China". British Food Journal, 120(9), 2182-2194. 